Provided for non-commercial research and education use. Not for reproduction, distribution or commercial use.

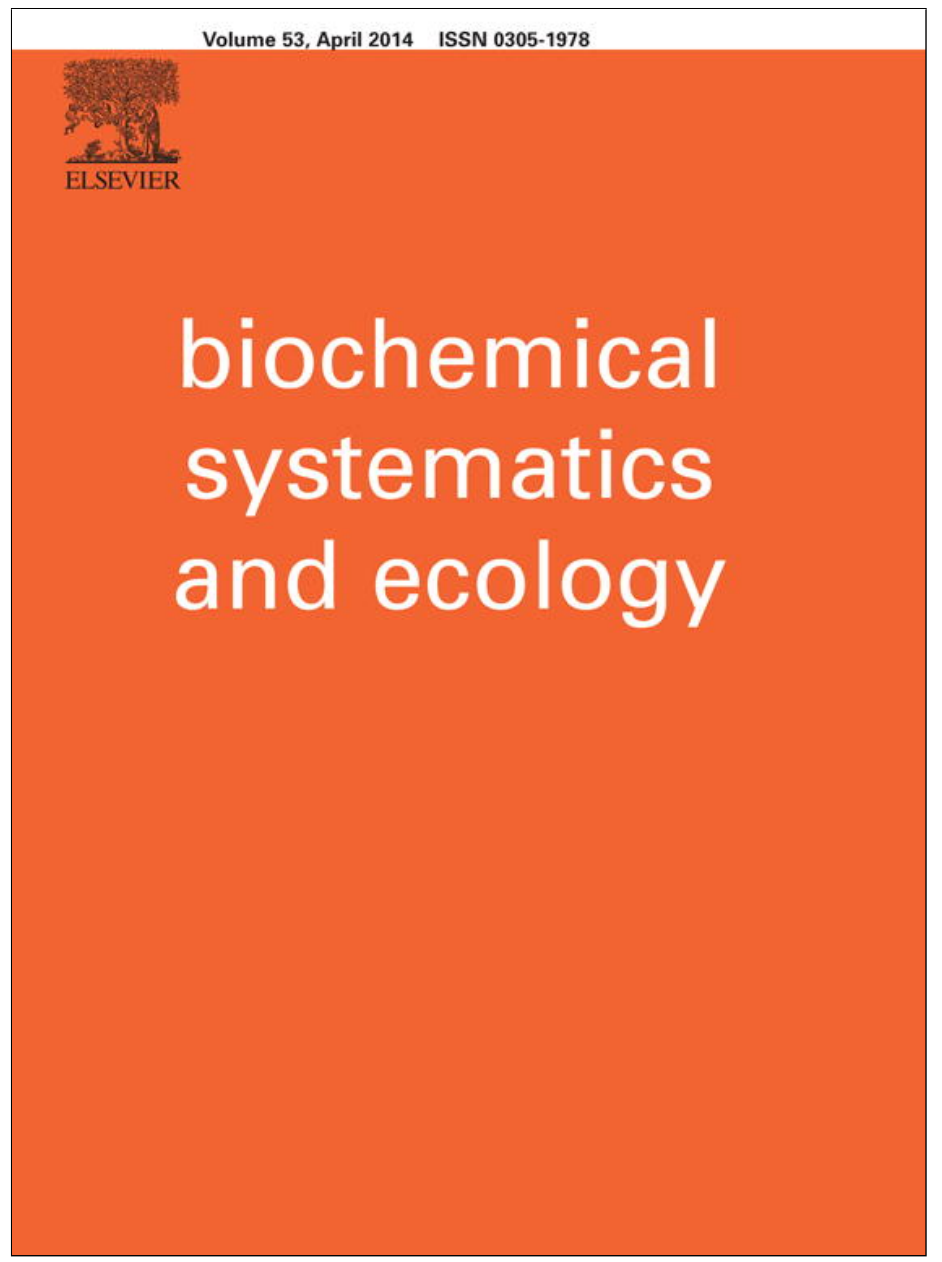

This article appeared in a journal published by Elsevier. The attached copy is furnished to the author for internal non-commercial research and education use, including for instruction at the authors institution and sharing with colleagues.

Other uses, including reproduction and distribution, or selling or licensing copies, or posting to personal, institutional or third party websites are prohibited.

In most cases authors are permitted to post their version of the article (e.g. in Word or Tex form) to their personal website or institutional repository. Authors requiring further information regarding Elsevier's archiving and manuscript policies are encouraged to visit:

http://www.elsevier.com/authorsrights 


\title{
Anthocyanin and flavonol profiles of Vitis vinifera L. cV Rufete grapes
}

\author{
Cristina Alcalde-Eon ${ }^{\text {a }}$, Ignacio García-Estévez ${ }^{\mathrm{a}}$, Alberto Martín-Baz ${ }^{\mathrm{b}}$, \\ Julián C. Rivas-Gonzalo ${ }^{\mathrm{a}}$, M. Teresa Escribano-Bailón ${ }^{\mathrm{a}, *}$ \\ a Grupo de Investigación en Polifenoles (GIP), Unidad de Nutrición y Bromatología, Facultad de Farmacia, Campus Miguel Unamuno, \\ E-37007 Salamanca, Spain \\ ${ }^{\mathrm{b}}$ Bodegas Viñas del Cámbrico S.A., E-37658 Villanueva del Conde, Salamanca, Spain
}

\section{A R T I C L E I N F O}

\section{Article history:}

Received 9 October 2013

Accepted 30 December 2013

Available online 25 January 2014

\section{Keywords:}

Vitis vinifera L. cv Rufete

Anthocyanins

Flavonols

HPLC-DAD-ESI-MSn

Hierarchical cluster analysis

\section{Subject and source}

The alteration of the rainfall pattern and the increase of the frequency of extremely hot days associated to global climate change are expected to have an important impact in agriculture. Grapevine, among other crops, seems to be particularly sensitive to these changes (Mira de Orduña, 2010). Wine producers are concerned about the negative impact of these changes in grapevine and, consequently in wine quality. Nevertheless, it has been reported that the impacts are not likely to be uniform across all varieties and regions (Jones et al., 2005). On the other hand, wine consumers demand not only quality but also typicity. As a consequence, the interest in autochthonous grape cultivars has been increasing during the last years. These autochthonous grape cultivars may provide typicity to the wine and may be better adapted to the changing conditions of the growing region. Nevertheless, a selection of the clones with the best potential should be performed. $V$. vinifera L. cv Rufete is autochthonous from La Sierra de Francia (MAGRAMA, 2013), a mountainous region located in the Southern west part of the Spanish province of Salamanca and which is a part of the Biosphere Reserve "Las Sierras de Bejar y Francia" designed by UNESCO in 2006. This cultivar is highly adapted to this region, with vineyards located in south-exposed terraces. Previous studies (Yuste et al., 2010) have revealed a high quality potential of this variety.

A preliminary clonal selection of this cultivar has been performed in the last recent years (García et al., 2005; Arranz et al., 2008 ) in order to select those with an adequate sanitary status that phenotypically and genetically matched with that cultivar. Clones were identified in accordance with the results of morphologic (71 OIV descriptors) and genetic studies (García et al., 2005; Yuste et al., 2006; Arranz et al., 2008; Santana et al., 2008). Some variability was observed among the different clones

\footnotetext{
* Corresponding author. Tel.: +34 923294537.

E-mail address: escriban@usal.es (M.T. Escribano-Bailón).
} 
probably related to the fact of growing in different vineyards. In order to avoid differences in the clones that might be due to the different initial location, the selected clones were all grown in a reference vineyard belonging to the "D.O.P. Vino de Calidad de Sierra de Salamanca". In addition to these identification techniques, the anthocyanin profile of grapes can also be used as a chemotaxonomic tool. Although the anthocyanin content can be affected by different external factors related to the location of the vineyard (soil, sunlight exposure, rainfall patterns...) the relation between the different pigments is quite stable and it differs from one variety to another (Revilla et al., 2001; Arozarena et al., 2002; García-Beneytez et al., 2002). In the present study the anthocyanin profile of nine Rufete clones all grown in the reference vineyard and with the same age was established. Furthermore, the flavonol composition was also determined since it has been reported that flavonol profiles can be an effective tool in differentiating varieties (Mattivi et al., 2006; Figueiredo-González et al., 2012).

\section{Previous work}

The genus Vitis L. (Vitaceae) comprises about 60 inter-fertile species existing almost exclusively in the Northern Hemisphere. Among them, the grapevine (V. vinifera $\mathrm{L}$.) is the only species extensively used in the global wine industry (This et al., 2006). Although it consist of thousands cultivars, only a few are used for wine production. The anthocyanin compositions of the most popular red grape varieties in the world (Cabernet-Sauvignon and Merlot among others) have been the subject of several studies (Revilla et al., 2001; Arozarena et al., 2002). In Spain, Tempranillo is the most cultivated red grape variety (MAGRAMA, 2009) and, therefore, there are a large number of papers dealing with the anthocyanin composition of this variety (Ortega-Meder et al., 1994; Revilla et al., 2001; Arozarena et al., 2002; Núñez et al., 2004). In addition, other majority varieties such as Bobal, Garnacha, Monastrell, Garnacha Tintorera have been the object of some studies (García-Beneytez et al., 2002; Castillo-Muñoz et al., 2009). In the last decade the interest on minority and autochthonous varieties has increased, also increasing the studies on their anthocyanin composition (Núñez et al., 2004; Pomar et al., 2005; FigueiredoGonzález et al., 2012). Unlike anthocyanin composition, flavonol composition has been studied in fewer red varieties (Mattivi et al., 2006; Castillo-Muñoz et al., 2007; Hermosín-Gutiérrez et al., 2011; Figueiredo-González et al., 2012). From all these studies it can be seen that there are differences in the anthocyanin and flavonol compositions among varieties that can be used to differentiate one red grape variety from another. The 3-glucosides, acetylglucosides, $p$-coumaroylglucosides and/or caffeoylglucosides of delphinidin, cyanidin, petunidin, peonidin and/or malvidin have been detected in different $V$. vinifera $\mathrm{L}$ varieties. Regarding flavonol composition, the 3-glucosides, 3-galactosides, 3-glucuronides and/or 3-rutinosides of quercetin, myricetin, kaempferol, laricitrin, isorhamnetin and/or syringetin and, more recently, the 3-acetylglucosides of quercetin and syringetin (Castillo-Muñoz et al., 2007) have been reported. Respecting Rufete variety, to our knowledge, there are no studies on its anthocyanin composition and there is only one study reporting the flavonol composition of this variety grown in Douro, Portugal (Andrade et al., 2001), in wich only myricetin 3-glucoside, quercetin 3-glucoside and kaempferol 3-rutinoside were reported to occur.

\section{Present study}

For each selected clone 50 grapes were collected at technological maturity from different bunches and from different parts of the bunch of a same grapevine. Skins were manually separated from the whole grapes and extracted three times (first time overnight, second and third times 30 min with sonication) with $\mathrm{MeOH}: \mathrm{HCl} 0.5 \mathrm{~N}$ (95:5). The extracts were gathered, concentrated under vacuum in a rotary evaporator and re-dissolved with acidified water $(\mathrm{pH}=1.3, \mathrm{HCl})$ to a final volume of $100 \mathrm{~mL}$. Samples were analysed in duplicate by means of HPLC-DAD-MS (Alcalde-Eon et al., 2006) after dilution (1/5) in acidified water $(\mathrm{pH}=1.3, \mathrm{HCl})$ and filtration $(0.45 \mu \mathrm{m})$. The identifications of the anthocyanins and flavonols were carried out from the chromatographic and spectral data and by comparison to literature (Alcalde-Eon et al., 2006; Castillo-Muñoz et al., 2007; Figueiredo-González et al., 2012). Twenty three different pigments and 14 flavonols were identified in the different clones (Tables 1 and 2). Among the pigments it is worth pointing out the detection of the cis isomers of some of the $p$ coumaroylglucosides and the detection of some anthocyanin derivatives, which are not usually reported in grapes. To be precise, three flavanol-anthocyanin $\left(\mathrm{F}-\mathrm{A}^{+}\right)$direct condensation pigments were detected. Anthocyanins were quantified from the chromatograms recorded at $520 \mathrm{~nm}$. Calibration curves of delphinidin, cyanidin, petunidin, peonidin and malvidin 3glucosides (Extrasynthèse, France) were used. The individual content (mg per $\mathrm{kg}$ of grape) of each individual pigment was calculated as well as the total pigment content that was the sum of all the individual contents (Table 1). The total anthocyanin content in the different Rufete clones ranged from 448.8 to $736.4 \mathrm{mg}$ per $\mathrm{kg}$ of grape with a mean content of $557.4 \mathrm{mg} / \mathrm{kg}$. Malvidin 3-glucoside was the major compound (mean content: $239.1 \mathrm{mg} / \mathrm{kg}$ ). The percentages represented by each type of aglycone showed that malvidin derivatives were the major group (circa $62 \%$ of the total pigment content), followed by petunidin (23.8\%), delphinidin (8.9\%), peonidin (4.6\%) and cyanidin (1\%) derivatives. Considering the type of pigment (monoglucosides, acetyl, $p$-coumaroyl and caffeoyl derivatives and flavanol-anthocyanin direct condensation products) the non-acylated monoglucosides were the most abundant group (69.6\%) whereas p-coumaroyl derivatives were the major group among the acylated ones (26.9\%). The mean ratio between cis and trans isomers of the $p$-coumaroyl derivatives was 7.2. Acetyl derivatives and caffeoyl derivatives represented $2.7 \%$ and $0.8 \%$ of the total content, respectively. The F- $\mathrm{A}^{+}$derivatives were present in very low percentages $(0.1 \%)$.

The 3-glucosides, 3-galactosides and 3-glucuronides of myricetin, quercetin and kaempferol were identified. Nevertheless, only the 3-glucosides of laricitrin, isorhamnetin and syringetin were detected, although the latter could not be quantified. The 
Table 1

Anthocyanins and anthocyanin-derived pigments determined in Rufete and Tempranillo clones.

\begin{tabular}{|c|c|c|c|c|c|c|c|c|c|c|c|c|c|}
\hline \multirow[b]{3}{*}{$\begin{array}{l}\text { Peak } \\
(520 \mathrm{~nm})\end{array}$} & \multirow[b]{3}{*}{$\begin{array}{l}\mathrm{t}_{\mathrm{R}}{ }^{\mathrm{a}} \\
(\mathrm{min})\end{array}$} & \multirow[b]{3}{*}{$\begin{array}{l}\mathrm{M}^{+\mathrm{a}} \\
(\mathrm{m} / z)\end{array}$} & \multirow[b]{3}{*}{ Compound $^{\mathrm{a}}$} & \multicolumn{4}{|l|}{ Rufete } & \multicolumn{3}{|c|}{ Rufete (older grapevine) } & \multicolumn{3}{|c|}{ Tempranillo (older grapevine) } \\
\hline & & & & \multicolumn{3}{|c|}{ Content (mg/kg) } & \multirow{2}{*}{$\frac{\%}{\text { Mean }^{b}}$} & \multicolumn{2}{|c|}{ Content (mg/kg) } & \multirow{2}{*}{$\frac{\%}{\operatorname{Mean}^{\mathrm{C}}}$} & \multicolumn{2}{|c|}{ Content (mg/kg) } & \multirow{2}{*}{$\frac{\%}{\operatorname{Mean}^{\mathrm{C}}}$} \\
\hline & & & & Mean $^{b}$ & $\operatorname{Min}^{\mathrm{b}}$ & $\operatorname{Max}^{\mathrm{b}}$ & & Mean $^{c}$ & SD & & Mean $^{c}$ & SD & \\
\hline 1 & 7.1 & 797 & F-A $A^{+} \mathrm{Mv}-3 g-G C$ & 0.1 & 0.1 & 0.2 & 0.0 & 0.1 & 0.0 & 0.0 & 0.4 & 0.1 & 0.0 \\
\hline 2 & 13.4 & 751 & $\mathrm{~F}-\mathrm{A}^{+} \mathrm{Pn}-3 \mathrm{~g}-\mathrm{C}$ & 0.0 & 0.0 & 0.1 & 0.0 & n.q. ${ }^{\mathrm{d}}$ & - & 0.0 & 0.0 & 0.0 & 0.0 \\
\hline 3 & 15.0 & 781 & $\mathrm{~F}-\mathrm{A}^{+} \mathrm{Mv}-3 \mathrm{~g}-\mathrm{C}$ & 0.3 & 0.2 & 0.3 & 0.1 & 0.2 & 0.0 & 0.1 & 0.4 & 0.0 & 0.0 \\
\hline 4 & 16.7 & 465 & Dp-3-glc & 35.8 & 29.2 & 58.2 & 6.4 & 21.7 & 0.9 & 6.1 & 172.9 & 5.8 & 13.9 \\
\hline 5 & 20.3 & 449 & Cy-3-glc & 4.0 & 2.9 & 6.7 & 0.7 & 2.3 & 0.0 & 0.7 & 17.5 & 0.4 & 1.4 \\
\hline 6 & 22.9 & 479 & Pt-3-glc & 91.9 & 78.0 & 135.2 & 16.4 & 59.7 & 2.4 & 16.8 & 317.3 & 8.9 & 25.6 \\
\hline 7 & 26.5 & 463 & Pn-3-glc & 18.0 & 13.7 & 25.7 & 3.2 & 11.2 & 0.4 & 3.2 & 43.2 & 1.3 & 3.5 \\
\hline 8 & 28.6 & 493 & Mv-3-glc & 239.1 & 188.1 & 307.7 & 42.9 & 160.7 & 5.9 & 45.3 & 444.9 & 12.1 & 35.9 \\
\hline 9 & 34.5 & 507 & Dp-3-acetylglc & 0.7 & 0.6 & 0.8 & 0.1 & 0.2 & 0.0 & 0.1 & 1.5 & 0.2 & 0.1 \\
\hline 10 & 38.3 & 491 & Cy-3-acetylglc & 1.2 & 0.9 & 1.5 & 0.2 & 0.5 & 0.1 & 0.1 & 1.7 & 0.1 & 0.1 \\
\hline 11 & 39.4 & 521 & Pt-3-acetylglc & 4.0 & 3.4 & 4.4 & 0.7 & 1.8 & 0.1 & 0.5 & 5.7 & 0.3 & 0.5 \\
\hline 12 & 40.4 & 611 & Dp-3-pcoumglc (cis ) & 1.2 & 1.0 & 1.4 & 0.2 & 0.6 & 0.0 & 0.2 & 1.9 & 0.0 & 0.2 \\
\hline 13 & 41.7 & 505 & Pn-3-acetylglc & 1.0 & 0.8 & 1.2 & 0.2 & 0.4 & 0.0 & 0.1 & 1.1 & 0.1 & 0.1 \\
\hline 14 & 42.3 & 535 & Mv-3-acetylglc & 7.8 & 6.3 & 9.4 & 1.4 & 3.0 & 0.3 & 0.8 & 6.4 & 1.0 & 0.5 \\
\hline 15 & 42.6 & 611 & Dp-3-pcoumglc (trans ) & 12.3 & 10.7 & 16.9 & 2.2 & 6.6 & 0.4 & 1.9 & 28.6 & 1.6 & 2.3 \\
\hline 16 & 43.0 & 625 & Pt-3-pcoumglc (cis) & 3.4 & 2.8 & 3.9 & 0.6 & 2.1 & 0.3 & 0.6 & 4.6 & 0.1 & 0.4 \\
\hline 17 & 43.9 & 625 & Pn-3-cafglc & 0.4 & 0.3 & 0.6 & 0.1 & 0.2 & 0.0 & 0.1 & 0.5 & 0.1 & 0.0 \\
\hline 18 & 44.4 & 655 & Mv-3-cafglc & 3.8 & 2.9 & 4.8 & 0.7 & 2.5 & 0.2 & 0.7 & 7.2 & 0.4 & 0.6 \\
\hline 19 & 44.7 & 595 & Cy-3-pcoumglc (trans) & 0.3 & 0.2 & 0.3 & 0.1 & 0.1 & 0.0 & 0.0 & 0.1 & 0.0 & 0.0 \\
\hline 20 & 45.1 & 625 & Pt-3-pcoumglc (trans) & 33.5 & 28.7 & 43.7 & 6.0 & 20.7 & 1.4 & 5.8 & 65.8 & 3.0 & 5.3 \\
\hline 21 & 45.3 & 639 & Mv-3-pcoumglc (cis) & 5.3 & 3.8 & 6.7 & 1.0 & 3.4 & 0.2 & 1.0 & 4.2 & 0.6 & 0.3 \\
\hline 22 & 46.9 & 609 & Pn-3-pcoumglc (trans ) & 6.0 & 4.4 & 7.9 & 1.1 & 3.6 & 0.3 & 1.0 & 10.7 & 1.0 & 0.9 \\
\hline \multirow[t]{2}{*}{23} & 47.2 & 639 & Mv-3-pcoumglc (trans) & 87.5 & 65.5 & 104.7 & 15.7 & 53.2 & 4.6 & 15.0 & 104.1 & 6.8 & 8.4 \\
\hline & & & Total & 557.4 & 448.8 & 736.4 & & 354.7 & 16.9 & & 1240.4 & 40.4 & \\
\hline
\end{tabular}

${ }^{\mathrm{a}} \mathrm{t}_{\mathrm{R}}$ : Retention time; $\mathrm{M}^{+}$: Molecular ion. F-A ${ }^{+}$: Flavonol anthocyanin direct condensation products; Dp: delphinidin; Cy: Cyanidin, Pt: Petunidin; Pn: Peonidin; Mv: Malvidin; glc: glucose; pcoum: $p$-coumaroyl; caf: caffeoyl.

b The mean content and mean percentage are calculated from the individual content and percentage of each compound in each of the nine selected clones analysed in duplicate $(n=18)$. Min: minimum content. Max: maximum content.

c The results are the mean values $(n=2)$ of a single clone.

d n.q. not quantified.

aglycones of myricetin and quercetin were also present in the samples as well a compound $(\mathrm{m} / z$ 481) eluting later than the aglycones whose UV-vis spectrum corresponded to a flavonol. However, the data obtained by HPLC-DAD-MS did not allow its identification. Flavonols were quantified from the chromatograms recorded at $360 \mathrm{~nm}$ using a calibration curve of quercetin 3-glucoside (Extrasynthèse, France). Table 2 shows the individual and total contents of flavonols as well as the percentages

Table 2

Flavonols determined in Rufete and Tempranillo clones.

\begin{tabular}{|c|c|c|c|c|c|c|c|c|c|c|c|c|c|}
\hline \multirow[b]{3}{*}{$\begin{array}{l}\text { Peak } \\
(360 \mathrm{~nm})\end{array}$} & \multirow[b]{3}{*}{$\begin{array}{l}t_{R}{ }^{a} \\
(\min )\end{array}$} & \multirow[b]{3}{*}{$\begin{array}{l}\mathrm{M}^{+\mathrm{a}} \\
(m / z)\end{array}$} & \multirow[b]{3}{*}{ Compound $^{\mathrm{a}}$} & \multicolumn{4}{|l|}{ Rufete } & \multicolumn{3}{|c|}{ Rufete (older grapevine) } & \multicolumn{3}{|c|}{ Tempranillo (older grapevine) } \\
\hline & & & & \multicolumn{3}{|c|}{ Content (mg/kg) } & \multirow{2}{*}{$\frac{\%}{\text { Mean }^{b}}$} & \multicolumn{2}{|c|}{ Content (mg/kg) } & \multirow{2}{*}{$\frac{\%}{\operatorname{Mean}^{\mathrm{C}}}$} & \multicolumn{2}{|c|}{ Content (mg/kg) } & \multirow{2}{*}{$\frac{\%}{\text { Mean }^{\mathrm{C}}}$} \\
\hline & & & & Mean $^{\text {b }}$ & $\operatorname{Min}^{\mathrm{b}}$ & $\operatorname{Max}^{\mathrm{b}}$ & & Mean $^{c}$ & SD & & Mean $^{c}$ & SD & \\
\hline 1 & 24.4 & 481 & Myricetin 3-galactoside & 1.5 & 1.1 & 2.0 & 2.7 & 0.9 & 0.0 & 2.1 & 4.2 & 0.2 & 3.0 \\
\hline $2^{\mathrm{d}}$ & 25.1 & $\begin{array}{l}495 \\
481\end{array}$ & $\begin{array}{l}\text { Myricetin 3-glucuronide } \\
\text { Myricetin 3-glucoside }\end{array}$ & 22.1 & 17.6 & 27.9 & 40.1 & 13.5 & 0.3 & 30.6 & 45.3 & 0.7 & 31.9 \\
\hline $4^{\mathrm{d}}$ & 32.6 & $\begin{array}{l}479 \\
465\end{array}$ & $\begin{array}{l}\text { Quercetin 3-glucuronide } \\
\text { Quercetin 3-glucoside }\end{array}$ & 18.8 & 10.6 & 37.7 & 32.5 & 20.5 & 0.4 & 46.2 & 56.9 & 1.1 & 40.0 \\
\hline 5 & 34.4 & 495 & Laricitrin 3-glucoside & 3.1 & 2.6 & 4.0 & 5.7 & 1.6 & 0.0 & 3.6 & 4.5 & 0.5 & 3.2 \\
\hline 6 & 36.4 & 449 & Kaempferol 3-galactoside & 0.9 & 0.8 & 1.1 & 1.6 & 0.8 & 0.1 & 1.8 & 3.6 & 0.5 & 2.6 \\
\hline $7^{\mathrm{d}}$ & 38.5 & $\begin{array}{l}463 \\
449\end{array}$ & $\begin{array}{l}\text { Kaempferol 3-glucuronide } \\
\text { Kaempferol 3-glucoside }\end{array}$ & 2.1 & 1.2 & 3.0 & 3.7 & 2.1 & 0.1 & 4.7 & 7.7 & 0.4 & 5.4 \\
\hline 8 & 38.9 & 319 & Myricetin & 1.8 & 1.5 & 2.9 & 3.3 & 1.2 & 0.2 & 2.6 & 6.2 & 0.4 & 4.4 \\
\hline 9 & 39.4 & 303 & Quercetin & 2.2 & 1.5 & 4.5 & 3.8 & 1.0 & 0.1 & 2.3 & 3.5 & 0.7 & 2.5 \\
\hline 11 & 41.4 & 481 & $\begin{array}{l}\text { Unknown } \\
\text { Total }\end{array}$ & $\begin{array}{l}1.2 \\
56.1\end{array}$ & $\begin{array}{l}1.0 \\
40.3\end{array}$ & $\begin{array}{l}1.5 \\
87.1\end{array}$ & 2.3 & $\begin{array}{l}0.7 \\
44.3\end{array}$ & $\begin{array}{l}0.0 \\
1.1\end{array}$ & 1.7 & $\begin{array}{l}2.1 \\
142.0\end{array}$ & $\begin{array}{l}0.0 \\
2.9\end{array}$ & 1.5 \\
\hline
\end{tabular}

${ }^{\mathrm{a}} \mathrm{t}_{\mathrm{R}}$ : Retention time; $\mathrm{M}^{+}$: Molecular ion.

$\mathrm{b}$ The mean content and mean percentage are calculated from the individual content and percentage of each compound in each of the nine selected clones analysed in duplicate $(\mathrm{n}=18)$. Min: minimum content. Max: maximum content.

c The results are the mean values $(n=2)$ of a single clone.

d The peak contains two compounds. Thus, the values shown in the table correspond to the sum of both compounds. 
represented by each one. The total flavonol content in the different Rufete clones ranged from 40.3 to $87.1 \mathrm{mg}$ per $\mathrm{kg}$ of grape with a mean content of $56.1 \mathrm{mg} / \mathrm{kg}$. Myricetin and quercetin derivatives were the major types of flavonols representing similar percentages of the total content in most clones (circa $40 \%$ each). Nevertheless, when considering the mean value of all the clones, myricetin derivatives were more abundant than quercetin ones (47.1\% and $39.3 \%$ respectively). Laricitrin derivatives showed similar percentages to kaempferol derivatives (circa 6\% each) whereas isorhamnetin derivatives represented less than $2 \%$ of the total content.

For comparative purposes, the anthocyanin and flavonol composition of grapes from an older Rufete grapevine growing in the same vineyard were determined. The total anthocyanin and flavonol contents ( $354.7 \mathrm{mg} / \mathrm{kg}$ and $44.3 \mathrm{mg} / \mathrm{kg}$, respectively) were lower than in the case of the younger selected clones. According to the type of aglycone the anthocyanin profile was very similar in younger and older grapes (older grapevine: malvidin derivatives, 63\%; petunidin, 23.8\%; delphinidin, 8.2\%; peonidin, $4.3 \%$; cyanidin, $0.8 \%$ ). However, slight differences were observed when considering the type of pigment with lower percentages of acylated anthocyanins in grapes from the older grapevine (non-acylated monoglucosides, 80.3\%; acetylglucosides, $1.3 \%$; $p$-coumaroylglucosides, $17.7 \%$; caffeoylglucosides, $0.6 \%$ ). The percentage of $\mathrm{F}-\mathrm{A}^{+}$condensation products and the cis/trans ratio were the same as in younger clones. Unlike in the case of the anthocyanin profile, the flavonol profile considering aglycones was quite different between grapes from younger and older grapevines (older grapevine: quercetin derivatives, 51.8\%; myricetin derivatives, 35.9\%; kaempferol derivatives, 6.6\%; laricitrin derivatives, 3.7\%; isorhamnetin derivatives, $2.1 \%)$. Quercetin derivatives were predominant in the latter ones whereas myricetin derivatives predominated in the grapes of the younger clones. A similar change was also observed for kaempferol and laricitrin derivatives: in the older clone kaempferol derivatives were more abundant than laricitrin ones. This might be indicative of a lower activity of the flavonoid $3^{\prime} 5^{\prime}$-hydroxylase in older grapevines. From these results it seems that flavonol profile is more affected by the age of the grapevine than anthocyanin profile.

Furthermore, the anthocyanin and flavonol profiles of all the Rufete clones were compared to those of a Tempranillo older clone grown in the same vineyard as the Rufete older one. The total anthocyanin and flavonol contents were much higher for Tempranillo (1240.4 mg/kg and $142.0 \mathrm{mg} / \mathrm{kg}$, respectively) than for Rufete clones. Differences were observed in the anthocyanin and flavonol profiles between both varieties. In relation to the former, Tempranillo grapes showed lower content of malvidin derivatives (45.7\%) and higher contents of delphinidin (16.5\%), cyanidin (1.6\%), and petunidin (31.7\%) derivatives than Rufete grapes. Peonidin derivatives represented similar contents in both varieties (4.5\%). The cis/trans ratio of the $p$-coumaroyl derivatives in Tempranillo was lower than that determined in Rufete grapes either coming from younger or from older grapevines. Further researches in other varieties have to be done in order to assess if this ratio can be used as a variety marker. Regarding flavonols, Tempranillo grapes showed higher percentages of quercetin $(46.7 \%)$ and kaempferol (8.1\%) derivatives and lower percentages of myricetin (39.8\%) and laricitrin (3.2\%) derivatives than the younger Rufete clones.

Hierarchical cluster analysis (HCA) was used as an unsupervised classification technique in order to verify if these differences allow the separation of the different types of samples in different groups. The similarity matrix was calculated using squared Euclidean distances and the Ward algorithm was used to generate the dendrogram. The results of applying HCA to either anthocyanin or flavonol percentual composition revealed a good separation between the Rufete and Tempranillo samples, which were grouped in two main clusters (Fig. 1). Furthermore, the use of the anthocyanin composition allowed the separation of the samples into three different groups. In this case, by choosing a relatively large and safe cutting value at the dissimilarity distance of 10 , one sub-group corresponding to the grapes from the Rufete older grapevine was formed within the cluster corresponding to Rufete grapes. If the flavonol composition was used in the HCA this separation was not possible as a consequence of the greater variability found in the levels of these compounds among the nine Rufete clones from younger grapevines.
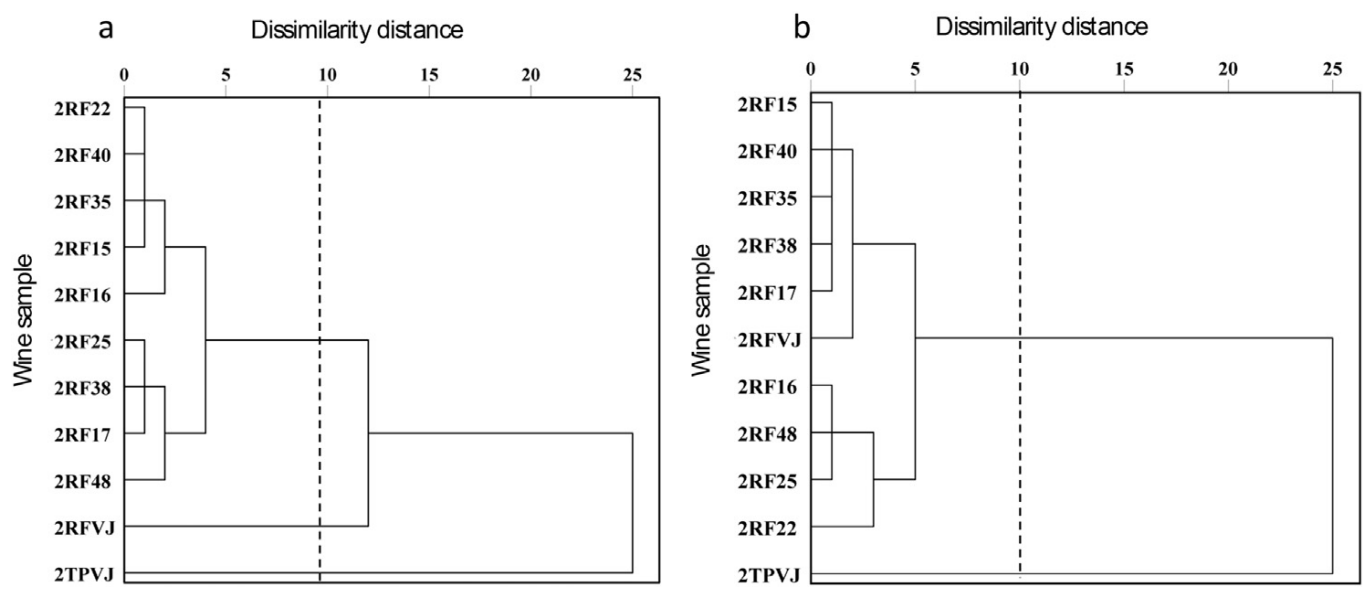

Fig. 1. Dendrograms obtained by hierarchical cluster analysis of the different grape samples from the mean individual percentages of anthocyanins and derived pigments (a) and flavonols (b). 2RFXX: grapes from the different clones of Rufete younger grapevines. 2RFVJ: Grapes from Rufete older grapevine. 2TPVJ: Grapes from Tempranillo older grapevine. 


\section{Chemotaxonomic importance}

The anthocyanin and flavonol profiles of Rufete red grapes ( $V$. vinifera L.) autochthonous from the UNESCO Biosphere Reserve "Las Sierras de Bejar y Francia" have been here reported for the first time. The knowledge of these profiles is useful not only for characterising the phenolic composition of the Rufete variety and for assessing its phenolic potential for wine production but also for chemotaxonomic purposes. In fact, the Hierarchical Cluster Analyses have revealed that the differences in the anthocyanin and flavonol profiles allow the separation between this autochthonous variety and Tempranillo, the red grape variety most grown in Spain. Furthermore, in the present study it has been shown that the anthocyanin composition may be used to differentiate among clones whereas it has not been possible with the flavonol profile, probably due to the greater variability in the levels among clones. The results of the present study contribute to a better knowledge of the Rufete variety. This information could be important for future breeding programmes. It illustrates the importance of conserving these autochthonous varieties because of their potential adaptability to the environmental changing conditions.

\section{Acknowledgements}

Thanks are due to the Spanish MICINN and FEDER (Project ref. AGL2011-30254-C02-01) for financial support. I. GarcíaEstévez thanks the Spanish “Ministerio de Educación, Cultura y Deporte” for the F.P.U. predoctoral scholarship.

\section{References}

Alcalde-Eon, C., Escribano-Bailón, M.T., Santos-Buelga, C., Rivas-Gonzalo, J.C., 2006. Anal. Chim. Acta 563, 238. http://dx.doi.org/10.1016/j.aca.2005.11.028. Andrade, P.B., Mendes, G., Falco, V., Valentão, P., Seabra, R.M., 2001. Food Chem. 73, 397. http://dx.doi.org/10.1016/S0308-8146(00)00309-5. Arozarena, I., Ayestarán, B., Cantalejo, M.J., Navarro, M., Vera, M., Abril, I., Casp, A., 2002. Eur. Food Res. Technol. 214, 303. http://dx.doi.org/10.1007/s00217001-0471-0.

Arranz, C., Rubio, J.A., Yuste, J., 2008. Vida Rural. 270 (46). http://www.magrama.gob.es/ministerio/pags/Biblioteca/Revistas/pdf_Vrural\%2FVrural_2008_ 270_46_51.pdf (accessed 01.10.13.).

Castillo-Muñoz, N., Fernández-González, M., Gómez-Alonso, S., García-Romero, E., Hermosín-Gutiérrez, I., 2009. J. Agric. Food Chem. 57, 7883. http://dx.doi. $\operatorname{org} / 10.1021 / \mathrm{j} f 9002736$.

Castillo-Muñoz, N., Gómez-Alonso, S., García-Romero, E., Hermosín-Gutiérrez, I., 2007. J. Agric. Food Chem. 55, 992. http://dx.doi.org/10.1021/jf062800k.

Figueiredo-González, M., Martínez-Carballo, E., Cancho-Grande, B., Santiago, J.L., Martínez, M.C., Simal-Gándara, J., 2012. Food Chem. 130, 9. http://dx.doi. org/10.1016/j.foodchem.2011.06.006.

García, S., Yuste, J., Arranz, C., Martín, A., Rubio, J.A., 2005. V Congresso Ibérico de Ciências Hortícolas. In: IV Congresso Iberoamericano de Ciências Hortícolas, vol. 2, ISBN 972-95881-9-8, p. 376.

García-Beneytez, E., Revilla, E., Cabello, F., 2002. Eur. Food Res. Technol. 215, 32.

Hermosín-Gutiérrez, I., Castillo-Muñoz, N., Gómez-Alonso, S., García-Romero, E., 2011. In: Ebeler, S.E., Takeoka, G.R., Winterhalter, P. (Eds.), Progress in Authentication of Food and Wine. ACS Symposium Series, Washington, DC, pp. 113-129. http://dx.doi.org/10.1021/bk-2011-1081.ch008.

Jones, G.V., White, M.A., Cooper, O.R., Storchmann, K., 2005. Clim. Change 73, 319. http://dx.doi.org/10.1007/s10584-005-4704-2.

MAGRAMA (Ministerio de Agricultura, Alimentación y Medio Ambiente), 2009. http://www.magrama.gob.es/es/estadistica/temas/estadisticas-agrarias/ Viñedo2009web_tcm7-207640.pdf (accessed 01.10.13.).

MAGRAMA (Ministerio de Agricultura, Alimentación y Medio Ambiente), 2013. http://www.magrama.gob.es/app/MaterialVegetal/fichaMaterialVegetal. aspx?idFicha $=540$ (accessed 01.10.13.).

Mattivi, F., Guzzon, R., Vrhovsek, U., Stefanini, M., Velasco, R., 2006. J. Agric. Food Chem. 54, 7692. http://dx.doi.org/10.1021/jf061538c.

Mira de Orduña, R., 2010. Food Res. Int. 43, 1844. http://dx.doi.org/10.1016/j.foodres.2010.05.001.

Núñez, V., Monagas, M., Gómez-Cordovés, M.C., Bartolomé, B., 2004. Postharvest Biol. Technol. 31, 69. http://dx.doi.org/10.1016/S0925-5214(03)00140-6. Ortega-Meder, M.D., Rivas-Gonzalo, J.C., Vicente, J.L., Santos-Buelga, C., 1994. Rev. Española Cienc. Tecnol. Aliment. $34,409$.

Pomar, F., Novo, M., Masa, A., 2005. J. Chromatogr. A 1094, 34. http://dx.doi.org/10.1016/j.chroma.2005.07.096.

Revilla, E., García-Beneytez, E., Cabello, F., Martín-Ortega, G., Ryan, J.M., 2001. J. Chromatogr. A 915, 53. http://dx.doi.org/10.1016/S0021-9673(01)00635-5.

Santana, J.C., Hidalgo, E., de Lucas, A.I., Recio, P., Ortiz, J.M., Martín, J.P., Yuste, J., Arranz, C., Rubio, J.A., 2008. Genet. Resour. Crop Evol. 55, 573. http://dx.doi. org/10.1007/s10722-007-9261-2.

This, P., Lacombe, T., Thomas, M.R., 2006. Trends Genet. 22, 511. http://dx.doi.org/10.1016/j.tig.2006.07.008.

UNESCO, 2006. http://www.unesco.org/new/en/natural-sciences/environment/ecological-sciences/biosphere-reserves/europe-north-america/ (accessed 01.10.13.).

Yuste, J., Alburquerque, M.V., García, S., Martín, A., 2010. Enoviticultura 3, 1.

Yuste, J., Martín, J.P., Rubio, J.A., Recio, P., Santana, J.C., Arranz, C., Ortiz, J.M., 2006. Span. J. Agric. Res. 4, 31. 